\title{
CSI culture: the evolution and influences of forensic science
}

\section{Proceeding}

The term "forensic science" in current American culture is now most commonly associated with television shows that focus on crime scene or death investigation. More correctly defined as the application of any field of science to criminal or civil proceedings in a court of law, forensic science has become a household topic due to the popularity of network television; most anyone can give an example of how the forensic sciences are used to solve crimes. This has lead to the development of what is called The CSI Effect which is defined within the legal community as "a phenomenon reported by prosecutors who claim that television shows based on scientific crime solving have made actual jurors reluctant to vote to convict when, as is typically true, forensic evidence is neither necessary nor available". ${ }^{1}$ More simply put, The CSI Effect gives jurors (i.e., members of the general public) an unrealistic expectation of the abilities of the forensic sciences. They are more demanding of physical evidence, particularly in criminal trials, which in turn raises the burden of proof for prosecutors, thereby diminishing the value of circumstantial or eyewitness evidence. A large scale study on The CSI Effect in 2008 showed that $80 \%$ of all American legal professionals felt their verdicts had been affected by TV shows and nearly half of all jurors who participated in the study felt that scientific evidence should be present in every criminal case. ${ }^{2}$ The extent to which forensic oriented television shows affect trial outcomes is widely dependent on the case itself, the available evidence, and the ability of the jurors to follow the standards of evidence. However, The CSI Effect is undoubtedly a factor to consider within the public's perception of the forensic sciences.

Despite its recent prime-time attention, forensic science has a rich history that spans centuries back to one of the first documented cases solved by forensic science as we know it today. In 1247 A.D. China, a villager was murdered using a common farming tool. Without much evidence to conduct an investigation, Sung Tz'u suggested that all the villagers bring their tools into the town square during the heat of the day, postulating that the remaining bits of blood and tissue on the blade from the commission of the murder would attract flies, which it did leading to a confession from the murderer. ${ }^{3}$ This initial use of forensic entomology was an excellent example of how scientific thinking can be used to solve a case, but not all early forensic techniques were as scientifically sound. Death determination itself was a difficult concept, and many medical professionals of the time struggled with finding an accurate method. Andreas Vesalius, often known as the father of modern anatomy, was documented as conducting a public autopsy on a still-living individual in 1564 which led to a new requirement that a physician must examine a body and officially pronounce death prior to autopsy. ${ }^{4}$ However, it did not specify the method by which death should be determined and many physicians and scientists had unique and often unreliable methods for making such a determination. One such method was documented in 1732 by a French anatomist, Dr. Jacob Winslow, who suggested that women should be arranged around a corpse and weep, wail, and gnash their teeth. He suggested that these women should, "If possible, shock the ears by hideous shrieks and
Volume 4 Issue 3 - 2017

\author{
Lerah Sutton, Jason Byrd \\ William R. Maples Center for Forensic Medicine, College of \\ Medicine University of Florida, USA
}

\begin{abstract}
Correspondence: Lerah Sutton, M.S., Graduate Assistant and Research Fellow, William R. Maples Center for Forensic Medicine, College of Medicine University of Florida, 4800 SW 35th Drive Gainesville, FL 32608, USA,

Email lerahsutton@ufl.edu
\end{abstract}

Received: March 21, 2017 | Published: March 22, 2017

excessive noises," using the assumption that a living person would be so overwhelmed by the noise that they would wake up and indicate their living state. ${ }^{5}$ Numerous other methods for death determination were employed over the next two centuries ranging from necrometers that were calibrated into units of "alive, probably dead, and dead" to the use of a mirror test where evidence of life would be indicated by the ability to fog a mirror with breath. Many of these methods such as the mirror test were notoriously unreliable. Dr. Paul Brouardel, a professor of medical jurisprudence, wrote in 1902 that "the abolition of respiration is the most untrustworthy of all the signs which have been invoked; you know the test of placing a mirror before the lips of a corpse" 6

A major hindrance to the progression of the forensic sciences came about in the "Dark Ages" where scientific advances and intellect generally declined. The Chart of Privileges established the Office of the Crowner in 925 A.D. which would eventually become the Office of the Coroner. Unlike death investigations of today, however, the Office of the Crowner was designed to protect the financial interests of the Crown, rather than conduct a thorough inquest into an individual's cause of death. Certain manners of death, including suicide, became a common law crime that resulted in tax penalties. Often, a decision regarding manner of death of was made based on the circumstances surrounding the death without an examination of the body, which led to rampant corruption. This practice continued for hundreds of years until 1533 when the Carolingian Code suggested that wounds should be opened and examined in the course of conducting a death investigation, particularly in cases of suspected homicide. $^{7}$ The profession of forensic death investigation in America continued to improve over the next several centuries, learning from Europe's lengthy investigative history, with the establishment of the first coroner's office, written records of autopsies, and eventually the establishment of the medical examiner system requiring a medical degree to perform an autopsy. These were major advances that helped to better preserve the integrity of the process of death investigation, making it more focused on figuring out what happened to the decedent (i.e., cause, manner, and mechanism of death) rather than associating death determination with financial gain. 
It is easy to understand the importance of victim identification when laid out in a 60 minute television program. However, this practice is much more difficult and nuanced in reality. Often, the crucial aspects of victimology - studying the victims themselves and the ways in which their identities influence the crime - are neglected or under-emphasized. This is a relatively new practice compared to the lengthy history of forensic science itself, but one that is valuable nonetheless. The methods of conducting a forensic death investigation may seem simple or straightforward, but that is rarely the case. When the circumstances surrounding a death are suspicious, everything must be examined and analyzed. Even the identity of a body may come into question, particularly if the body is decomposed, skeletonized, or otherwise difficult to visually identify. However, identification is merely the first step toward a successful investigation. It is crucial to understand who the victim was in life to fully grasp the implications of how they died; the two are often related. This helps investigators to understand why someone might become a victim, what relationship they may have had with the perpetrator, and may, in turn, shed light on the circumstances surrounding their death. ${ }^{8}$

Every crime is unique from its evidence to its victims, and must be treated as such. There is, however, an overarching similarity in the methodologies within the forensic sciences that speaks to a consistency and reliability of crime scene investigation procedures all based within the scientific method. Taking the same approach to every crime scene and death investigation allows for a better understanding of the uniqueness present within each scene. Forensic science, when done correctly, can provide a balance between potentially conflicting ideas and parties involved in an investigation which may, in turn, have significant implications for victimology and social justice. Further, it may act as a counter-balance to prevent bias based on any presumptions (e.g., guilt vs. innocence) and instead allow for the unbiased operation and investigation of the scene as the evidence presents it. One must first understand what is normal to be able to successfully identify what is abnormal. It is this uniqueness that mirrors the identity of the victims themselves and allows an investigation to come full-circle, bringing justice to the victim and giving a voice to the voiceless. Although popular television shows may not always accurately depict the reality of crime scene investigations, they do portray at least one consistently correct adage: On a crime scene, as in life, things are not always what they seem.

\section{Acknowledgments}

None.

\section{Conflicts of interest}

None.

\section{References}

1. Gerald NH, Hill K. Nolo's Plain-English Law Dictionary. NOLO. 2009; $1-505$.

2. Donald ES. The CSI Effect: Does It Really Exist? NIJ Journal. 2008;259.

3. Bol PK, Brian EM. The Washing Away of Wrongs [Hsi Yuan Chi Lu, by Sung Tz'u (1186-1249)]: Forensic Medicine in Thirteenth-Century China. The Journal of Asian Studies. 1983;42(3):643-644.

4. Andreas V, Garrison DH, Hast MH, et al. The Fabric of the Human Body: An Annotated Translation of the 1543 and 1555 Editions. Karger. 2014

5. Jacob B. Exposition anatomique de la structure de corps humain. 1732

6. Brouardel P, Benham FL. Death and Sudden Death. W. Wood \& Company. 1902.

7. Ramsland KM. Beating the Devil's Game: A History of Forensic Science and Criminal Investigation. 2007;1-300.

8. Pettler LG. Crime Scene Staging Dynamics in Homicide Cases. CRC USA. 2016;1-416. 